\title{
RESENHA DA OBRA LE DROIT SAISI PAR LA PHOTOGRAPHIE, DE BERNARD EDELMAN ${ }^{1}$
}

\author{
Gabriel Gualano de Godoy
}

REVIEW OF THE BOOK LE DROIT SAISI PAR LA PHOTOGRAPHIE, BY BERNARD EDELMAN

\section{RESENHA}

EDELMAN, BERNARD. LE DROIT SAISI PAR LA PHOTOGRAPHIE. PARIS: Flammarion, 1973.

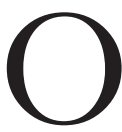

que somos nós para o direito? Para o jurista francês Bernard Edelman, o ato de nascimento de toda a ideologia jurídica do Ocidente pode ser identificado com o postulado segundo o qual o homem é, por natureza, um sujeito de direito. A função desse enunciado é transformar a arte do direito em uma prática abstrata.

O direito começa pela pessoa que é todo o sujeito de direito, ou seja, a pessoa apta a ser titular de direitos e obrigações. A pessoa humana será sujeito de direitos independentemente de sua vontade. O homem, então, parece ter um poder jurídico que lhe é conferido pelo conceito de direito objetivo. E é a existência de um sujeito que faz o direito, o Estado, que dá coerência e unidade à norma de direito o que, por sua vez, implica a "sujeição do sujeito de direito ao Sujeito".

Oculto nessas ideias está o funcionamento de uma ideologia, uma tautologia que faz com que os juristas vejam nos conceitos jurídicos o verdadeiro fundamento das relações de propriedade reais, sem perceber a trama das relações de produção.

Ao tratar dos problemas jurídicos levantados pelo desenvolvimento técnico 
e econômico do cinema e da fotografia, Edelman apresenta a seguinte tese: "a produção jurídica é a produção de um sujeito cuja essência é a propriedade e cuja atividade só pode ser a de um proprietário privado". Assim sendo, haveria um conteúdo contraditório na propriedade literária e artística, onde há "sobreposição sobre uma propriedade já estabelecida”.

De acordo com a lente marxista de Edelman, o sujeito faz seu o real que é também de outra pessoa, pois o fotógrafo, por exemplo, capta na lente objetiva a propriedade de outro: imagem, movimento, vida privada. Esse movimento marca o que Edelman denominou de “sobre-apropriação do real”. A criação do artista, em certo momento, demandou a criação de um novo direito. Foi nesse sentido que o direito do autor passou a ser classificado como direito subjetivo da personalidade do artista. Contudo, como demonstrou Edelman, com a fotografia e com o cinema, a captação de uma imagem é a captação também de um direito da personalidade, de uma expressão da singularidade de um sujeito de direito. Nesse passo, opera-se uma sobre-apropriação do real.

Para provar seu argumento, o autor problematizou duas teses. Primeira tese: a propriedade literária e artística é uma propriedade. Segunda tese: essa formapropriedade produz o sujeito de direito.

Com seu primeiro teorema, Edelman mostra como, através da ficção jurídica da propriedade imaterial, a criação invisível, fruto do pensamento do homem, transforma-se em algo visível, em propriedade privada. Já com o segundo teorema,
Edelman mostra como o real é produção do sujeito, pois o estatuto da vontade postula a apropriação privada de toda a natureza. O domínio público é propriedade comum, ou seja, pode-se fotografar aquilo que está em sua vista e sua apropriação não prejudica ninguém. Ora, se um autor limitar-se a reproduzir o domínio público não haverá proteção ao seu direito autoral, pois é preciso não apenas reproduzir, mas também criar, produzir o real para usufruir da proteção jurídica.

$\mathrm{Na}$ produção do fotógrafo e do cineasta encontra-se um real que já pertence a outrem. O direito foi, com isso, surpreendido, porque até certo ponto só conhecia aquela arte dita "manual". A primeira resposta jurídica quanto à possibilidade de se considerar o trabalho do fotógrafo como sobre-apropriação do real foi negativa. Isso porque toda a criação artística dos primeiros fotógrafos e cineastas seriam apenas criações maquínicas; era como se fosse um trabalho sem alma. Contudo, em um segundo momento, passou-se a reconhecer alma a esse trabalho tendo em vista, especialmente, as necessidades de proteção legal da indústria fotográfica e cinematográfica.

$\mathrm{Na}$ etapa histórica do nascimento jurídico da fotografia e do cinema há uma relação íntima do homem com a máquina. Esse processo puramente mecânico foi desqualificado e, em consequência, no plano jurídico, a arte produtora da máquina não poderia ser equiparada à arte criadora de um pintor, que produz com alma.

Assim, em um primeiro momento, "a actividade de um homem pode ser a 
simples actividade de uma máquina e a sua própria actividade o transforma em máquina”. Mas essa resistência do direito começa a se transformar com a efetiva tomada do cinema e da fotografia pela indústria. Aí, passa-se de um trabalho sem alma para um trabalho artístico como exigência das relações de produção. Sua importância econômica impôs essa mudança.

Narra Edelman que na Alemanha, a partir de 1880, começou a ocorrer um crescente aumento no número de processos judiciais envolvendo fotógrafos. O mesmo se passou na França. Naquela época, cerca de 50 mil pessoas viviam da fotografia e não era sequer possível recusar-lhes proteção jurídica. Assim, para o autor: "o reconhecimento da qualidade de fotógrafo se tornava uma necessidade da indústria. Estas novas forças produtivas tinham de encontrar meio da sua eficácia. Essa eficácia disfarçava-se, precisamente aqui, de estética”. E essa estética subordinada ao comércio obriga tanto o reconhecimento do direito do autor quanto sua necessária limitação.

O capital investido na indústria do cinema e da fotografia impulsionou a mudança de tratamento desses dois meios pelo direito, sendo este o solo em que ocorreu todo o processo de mudança de orientação jurisprudencial que criou os direitos da personalidade.

Para que a fotografia alcançasse o âmbito dos sujeitos, os tribunais utilizaram o conceito "marca da personalidade" e dissociaram a o olhar do fotógrafo do processo maquínico. De certo modo, a substituição da máquina pela técnica operou a subjetivação da primeira, cujo trabalho transformou-se também em trabalho do sujeito.

Portanto, a máquina se tornou meio de ser do sujeito e lugar de trabalho humano. Mas a fotografia só mereceria proteção jurídica se apresentasse uma marca intelectual de seu autor. Assim, conforme Edelman, "se o aparelho fotográfico entrou claramente no âmbito do sujeito, é, por seu turno, dominado por ele: aqui como lá o real só pertence ao sujeito desde que este o invista: (se apodere dele)". E deixando o real de ser criado pelo sujeito - perdendo seu caráter de individualidade e criação -, a máquina volta a ser simplesmente uma máquina de reprodução.

Assim sendo, as forças produtivas do capital realizam-se justamente no lugar do sujeito de direito. Toda a produção é produção de um sujeito, qualificada como produção de propriedade privada. Edelman demonstra como Marx tinha razão ao perceber que o homem como sujeito de direito toma posse da natureza como propriedade privada. Ora, quando foi exigido pelas forças de produção que a apropriação do real pela fotografia e pelo cinema fosse por lei protegida, por uma prática nitidamente burguesa, bastou dizer que a "máquina transmite a alma do sujeito".

Ao estudar o destino da categoria sujeito de direito e o destino do real, o autor concluiu que "a socialização da indústria cinematográfica produz a socialização do sujeito criador, do sujeito coletivo". Para ele, o capitalismo teve 
que adaptar seus métodos de produção, distribuição e consumo ao produto intelectual representado pelo filme.

No cinema norte-americano, por exemplo, isso transcorre de duas formas: há monopolização da matériaprima intelectual e essa monopolização se dá pelo contrato, pois a atividade criadora humana pode ser objeto de um contrato tal como seus autores. É o contrato o "instrumento privilegiado da dominação capitalista”, que designa "a mercantilização do homem enquanto objecto de direito". O filme não passa de uma mercadoria e, como tal, é submetido à lei do lucro.

Seguindo a análise de Edelman, a monopolização dos meios de produção pelo capital revelou uma relação jurídica curiosa, uma relação que precisou reconhecer o sujeito coletivo.

No início, os tribunais reconheceram o produtor como único autor do filme. A luta com os autores, no entanto, fez nascer uma combinação de produção intelectual e industrial, surgindo, então, a figura de um sujeito coletivo.

Ainda assim a arte não teria deixado de ser um produto do capital, a ponto de o direito confessar que o verdadeiro sujeito criador é também o próprio capital. Para que a trama ganhasse um desfecho, o capital não pôde prescindir do sujeito de direito, que é em realidade o seu sujeito. O contrato fez do artista um proletário e o capital tornou-se parte essencial da obra, indivisível e representada também pelo produtor.

Crescendo as forças produtivas na indústria cinematográfica, cresceu também a socialização do sujeito produtor e, da mesma forma, o sujeito coletivo indicou o que era cinema. Há, nesse passo, uma coexistência forçada entre indústria e arte. Observou Edelman que, com o aparecimento do sujeito coletivo, foi provocada uma contradição no cinema burguês: a obra é confessadamente coletiva, o sujeito de direito criador é pulverizado em sujeitos de direito criadores.

Então, o aparelho cinematográfico é um aparelho ideológico que representa a própria ideologia através dele mesmo, o cinema. A máquina se faz sujeito, reproduzindo sua própria essência. Ou seja, a máquina não reproduz simplesmente a ideologia e, sim, a ideologia produz a máquina.

Como foi dito, os fatos, para se tornarem propriedade do sujeito, devem ter sido criados por ele. A questão que Edelman coloca é como se pode criar ou produzir algo que verdadeiramente acontece? Seu exemplo é o filme da morte do presidente norte-americano John Kennedy, cujas imagens, em tempo real, foram depois utilizadas para ilustrar um livro sobre esse acontecimento. Quando o autor da foto resolveu reivindicar em juízo os direitos sobre a imagem, precisou responder ao argumento da defesa, que dizia ser o fato em questão um acontecimento de domínio público, um fato não produzido nem criado, um fato tão-somente reprodutor do que se passara na história. Mas os juízes deram razão ao autor das fotos sob o argumento de que é preciso diferenciar fundo e forma e também dizendo que o "proprietário" da filmagem reivindicava 
não o direito sobre o acontecimento, mas, sim, sobre as formas de expressão materializadas no filme. Com isso, Edelman nota que se chega a um novo estágio: o de uma "sobre-apropriação do real” que se constitui "pelo simples registro do real".

Edelman passa, então, a analisar a forma mercantil do sujeito, a forma capital da vida, considerando que o sujeito que reproduz vai produzir também seu próprio concorrente: o sujeito que é reproduzido. Nas palavras dele: “o direito do fotógrafo sobre a sua foto produz o direito do fotografado sobre a sua imagem".

A propriedade privada de um sujeito encontra a do outro e a noção de propriedade incorpora-se no próprio homem. O sujeito de direito reproduzido é uma decomposição mercantil da categoria sujeito de direito. A pessoa torna-se forma geral da mercadoria.

O homem é, ao mesmo tempo, sujeito e objeto de direito, e qualquer produção humana é produção de um operário. Não se discute que o homem é proprietário de si mesmo, mas isso leva o direito a nos dizer que o sujeito existe como representante da mercadoria que possui, de si próprio como mercadoria. O patrimônio moral do homem reflete exatamente isso: "o homem é para si próprio o seu próprio objeto”.

O que Edelman mostra é que, no capitalismo, o sujeito deve poder levar ao mercado os seus atributos, seu corpo, seu nome, seu direito moral, sua honra, sua imagem, sua vida privada. A alienação de si produz uma liberdade e o sujeito é objeto de direito permanecendo livre em si próprio. A propriedade é para o direito essência do homem e o ato de vender-se realizaria a liberdade do homem. Para ele, o sujeito de direito é um sujeito que quer vender-se, ou não.

Edelman assim conclui a estratégia adotada pelo direito: o homem pode vender--se desde que o faça em nome de um direito de personalidade. E a prática conduz a outra análise inevitável: todos os atributos da pessoa são direitos contratualmente protegidos porque, uma vez violados, geram direito à reparação. E a categoria sujeito de direito é histórica porque o processo capitalista o transforma em seu último produto: o objeto de direito. Nas palavras do autor: "o sujeito é a propriedade privada historicizando-se que se distribui nos sujeitos da história”. A história é também propriedade dos sujeitos de direito e a essência histórica do homem é a propriedade privada.

Para produzir um direito do cinema e da fotografia, foram colocadas em funcionamento categorias da propriedade literária e atributos da personalidade, sempre através da figura do sujeito de direito.

É dessa maneira que o direito fixa as normas de funcionamento do conjunto das relações sociais e, ao mesmo tempo, torna eficaz a ideologia jurídica, aquela relação imaginária dos indivíduos com as relações sociais em geral. Por isso mesmo, para Edelman, o direito vive de uma contradição: faz valer a produção capitalista em nome de propriedades privadas, as quais são justamente fruto da exploração do homem pelo homem. 
$\mathrm{Na}$ esfera da circulação, todos os homens, seus corpos e almas são mercadorias ou valores de troca. O produto do trabalho do homem é mercadoria e pode ser trocado por outra mercadoria. O direito toma essa esfera de circulação, espaço da sociedade civil, como algo natural e os indivíduos como valores de troca.

Apropriando-se das lições de Marx, o autor reafirmou que o sistema do valor de troca é o que significa o sistema da liberdade e da igualdade, e que dele nascem contradições imanentes. O homem é concretamente explorado pelo homem e do operário é retirada a mais-valia. Cria-se, juntamente com isso, a ilusão de que tal liberdade e igualdade são necessárias e "toda a ideologia burguesa consiste em ocultar a contradição imanente dessa liberdade e dessa igualdade, que se transmudam no seu contraditório: a escravidão e a exploração”.

$\mathrm{Na}$ esfera da circulação tudo se passa entre sujeitos que são, em última análise, sujeitos do grande Sujeito, que é o mercado, o capital.

Edelman mostrou isso com dois enunciados. O primeiro descreve o direito e fixa a esfera da circulação como um dado natural. O segundo enunciado descreve que o direito, ao assegurar a circulação como um dado natural, torna possível a produção. Ou seja: o sujeito da sociedade civil nada mais é do que um sujeito de direito proprietário; a troca é a relação jurídica fundamental e a produção social do homem é a produção de um sujeito de direito que tem a forma geral da mercadoria.
De acordo com Edelman, o que Marx chamou de ideológica é a ligação entre sociedade civil e esfera da circulação. E a redução do processo social a uma aparência de circulação é o local de encontro das ideologias burguesa e jurídica. As categorias que fundamentam a sociedade civil - propriedade privada, sujeito, vontade, liberdade, igualdade são especificadas pelo direito e seu aparelho de coerção estatal.

$\mathrm{Na}$ relação capitalista, a mercadoria força de trabalho aparece no mercado sempre voltada à circulação. Assim, conforme Edelman, o real captado pela fotografia ou pelo cinema também foi apreendido pelas categorias jurídicas e pelo capital.

A circulação no mercado abole as diferenças entre as pessoas concretas, pois todos os sujeitos abstartos são iguais e livres: "todo sujeito de direito é igual a qualquer sujeito de direito". E é o contrato o instrumento jurídico que permite a exploração do homem pelo homem, porque entendido como fruto da vontade humana de contratar.

O homem é, assim, ponto de partida e de chegada da ciência burguesa do direito, sempre compreendido através da noção abstrata de sujeito de direito. Os direitos da personalidade de um homem são aqueles direitos personalíssimos, pois são aquilo que resta do sujeito, a última mercadoria que pode qualificar um homem de sujeito.

Assim visto, o direito transparece as contradições de sua prática e os limites de sua ciência. O que Edelman chamou de ciência burguesa do direito preencheu o 
espaço público, lugar da luta de classes. Então, a crítica de noções ideológicas do direito traz em si a morte dessa ciência burguesa, cabendo aos juristas denunciar a ilusão do sistema que transforma o homem em mercadoria, sob o véu de uma pretensa liberdade.

Essa foi a tarefa que Edelman pretendeu cumprir e que poderia ser sintetizada assim: "Sendo o homem reconhecido 'como essência' da propriedade, qualquer produção do homem é a produção de um proprietário: melhor, de uma propriedade que frutifica e produz a renda e o lucro. A valorização dele próprio constitui o seu capital. Não um vulgar capital-dinheiro, mas um capital digno da essência humana: um capital "moral'”. 2

NOTAS

1 EDELMAN, Bernard. Le droit saisi par la photographie. Paris: Flammarion, 1973.

Disponível também em português: EDELMAN, Bernard. O direito captado pela fotografia. Trad. Soveral Martins e Pires de Carvalho. Coimbra: Centelha, 1976.

2 EDELMAN, Bernard. O direito captado pela fotografia. Trad. Soveral Martins e Pires de Carvalho. Coimbra: Centelha, 1976, p. 94.

Gabriel Gualano de Godoy

Rua Visconde do Rio Branco, n. 1799, apto. 122

Centro - 80420-210

Curitiba - PR - Brasil

gabrielgualanolgmail.com
BAChAREL E MESTRE em DiREITO PELA Universidade FEDERAL do PARANÁ (UFPR)

PESQUisador da UNIVERSIDADE FEDERAL dO PARANÁ (UFPR) 